\title{
Is traumatic brain injury a risk factor for neurodegeneration? A meta-analysis of population-based studies
}

\author{
Chi-Hsien Huang ${ }^{1,2}$, Chi-Wei Lin ${ }^{1,2}$, Yi-Che Lee ${ }^{2,3}$, Chih-Yuan Huang ${ }^{4}$, Ru-Yi Huang ${ }^{1,2}$, Yi-Cheng Tai ${ }^{5}$, \\ Kuo-Wei Wang ${ }^{2,6}$, San-Nan Yang ${ }^{2}$, Yuan-Ting Sun ${ }^{7}$ and Hao-kuang Wang ${ }^{2,6^{*}}$ (D)
}

\begin{abstract}
Background: To determine the association of prior traumatic brain injury (TBI) with subsequent diagnosis of neurodegeneration disease.

Methods: All studies from 1980 to 2016 reporting TBI as a risk factor for diagnoses of interest were identified by searching PubMed, Embase, study references, and review articles. The data and study design were assessed by 2 investigators independently. A meta-analysis was performed by RevMan 5.3.

Results: There were 18 studies comprising 3,263,207 patients. Meta-analysis revealed a significant association of prior TBI with subsequent dementia. The pooled odds ratio (OR) for TBI on development of dementia, FTD and TDP-43 associated disease were 1.93 (95\% Cl 1.47-2.55, $p<0.001)$, 4.44 (95\% Cl 3.86-5.10, p < 0.001), and 2.97 (95\% Cl 1.35-6.53, p < 0.001). However, analyses of individual diagnoses found no evidence that the risk of Alzheimer's disease, and Parkinson's disease in individuals with previous TBI compared to those without TBI.

Conclusions: History of TBI is not associated with the development of subsequent neurodegeneration disease. Care must be taken in extrapolating from these results because no suitable criteria define post TBI neurodegenerative processes. Therefore, further research in this area is needed to confirm these questions and uncover the link between TBI and neurodegeneration disease.
\end{abstract}

Keywords: TBI, Dementia, Neurodegeneration, Meta-analysis

\section{Introduction}

Traumatic brain injury (TBI) occurs when an external force injures the brain. Motor vehicle accidents cause most TBIs in young adults, while falls are the leading cause of TBIs in people over 65 years of age [1]. Owing to the increasing use of motor vehicles in developed countries, the incidence of TBI is rapidly growing. TBI is a major cause of death and disabilities-especially in children and young adults-that result in high societal costs $[1,2]$. Men sustain TBIs more frequently than women do. These observations suggest that TBIs result in major health and socioeconomic problems throughout the

\footnotetext{
*Correspondence: ed101393@gmail.com; ed101393@edah.org.tw

${ }^{2}$ School of Medicine for International Students, I-Shou University, Kaohsiung, Taiwan

${ }^{6}$ Department of Neurosurgery, E-Da Hospital, I-Shou University, No.1, Yida Road, Jiaosu Village, Yanchao District, Kaohsiung City 82445, Taiwan
} Full list of author information is available at the end of the article world. Indeed, the World Health Organization has reported that traffic accidents are the third highest contributor to the global burden of disease and injury $[1,2]$.

Neurological damage occurs not only at the moment of impact (primary injury) in a TBI, but also it further develops overtime post-impact. Several processes, such as neurotransmitter release, free-radical generation, calcium-mediated damage, gene activation, mitochondrial dysfunction, and inflammatory responses, have been investigated in studies of the secondary injuries that are associated with TBI [3-5]. These mechanisms might occur continuously over patients' lifetimes. Interestingly, a history of TBI has been reported to increase the incidence of Alzheimer disease (AD) [6] and other neurodegenerative conditions, including Parkinson's disease (PD) [7], amyotrophic lateral sclerosis (ALS) [8],

(c) The Author(s). 2018 Open Access This article is distributed under the terms of the Creative Commons Attribution 4.0 International License (http://creativecommons.org/licenses/by/4.0/), which permits unrestricted use, distribution, and 
and frontotemporal dementia (FTD) [5]. However, other studies have yielded contradicting results [9-13].

The goal of our study was to determine whether TBI was associated with an increased risk of neurodegeneration by conducting a systematic review of cohort studies of patients with TBI. In addition, we examined which neurodegenerative process occurred most often.

\section{Methods}

\section{Data sources}

We conducted systematic literature searches of the association between neurodegeneration and TBI in the Medical Literature Analysis and Retrieval System Online (MEDLINE ${ }^{\circ}$ /PubMed (US National Library of Medicine, National Institutes of Health, Bethesda, MD; http:// www.ncbi.nlm.nih.gov/pubmed) database and Excerpta Medica Database (EMBASE ${ }^{\bullet}$ Elsevier, Amsterdam, Netherlands; http://www.elsevier.com/solutions/embase-biomedical-research). We used the following keywords to generate a list of potentially useful studies: ([traumatic brain injury] OR [head injury] OR [brain injury] OR [TBI]) AND ([neurodegeneration] OR [cognitive dysfunction] OR [dementia] OR [alzheimer's disease] OR [AD] OR [parkinson's disease] OR [parkinsonism] OR [frontotemporal dementia] OR [Amyotrophic Lateral Sclerosis]) [14-16]. The search was performed through December 2016. The reference lists in the selected studies, as well as the list of studies included in earlier meta-analyses on similar topics, were reviewed for additional references. This review considered observational studies, and case series.

\section{Inclusion criteria}

We included published articles on the risk of neurodegeneration, including cognitive dysfunction, dementia, $\mathrm{AD}, \mathrm{PD}, \mathrm{FTD}$, and ALS, among individuals with TBIs compared with the risk of neurodegeneration in individuals in a nonbrain-injured population-based control group. A risk estimate was calculated with the data provided in the article. TBI was not limited in accordance with its severity.

\section{Exclusion criteria}

Studies were excluded if (1) they were reviews, case reports, or case series; (2) they only consisted of a follow-up study of a cohort of patients with brain injury with no comparison group; (3) there was a non-population-based control group (i.e., a patient control group); or (4) insufficient information was available to allow for calculations of risk estimates [14-16].

\section{Study selection}

The outcomes recorded were neurodegeneration, dementia, PD, and transactive response DNA-binding protein of $43 \mathrm{kDa}$ (TDP-43) aggregation-associated disease. ALS and FTD, which are closely related conditions with overlapping clinical, pathological,

Table 1 Individual for all included studies

\begin{tabular}{|c|c|c|c|c|c|c|}
\hline$\overline{\operatorname{Ref}}$ & Author, year & Type & $\begin{array}{l}\text { TBI+ } \\
\text { Neurodegeneration }+\end{array}$ & $\begin{array}{l}\text { TBI+ } \\
\text { Neurodegeneration - }\end{array}$ & $\begin{array}{l}\text { TBI- } \\
\text { Neurodegeneration }+\end{array}$ & $\begin{array}{l}\text { TBI- } \\
\text { Neurodegeneration - }\end{array}$ \\
\hline 20 & Mehta KM, et al. 1999 & Dementia (APOE) & 11 & 788 & 118 & 5728 \\
\hline 21 & Luukinen H, et al. 2005 & & 5 & 3 & 29 & 115 \\
\hline 22 & Sundström A, 2007 & & 25 & 46 & 156 & 316 \\
\hline 23 & Luukinen H, et al. 2008 & & 11 & 17 & 14 & 92 \\
\hline 25 & Wang HK, 2012 & Dementia & 1196 & 43,729 & 3499 & 221,186 \\
\hline 26 & Gardner RC, et al. 2014 & & 4361 & 47,438 & 6610 & 108,891 \\
\hline 27 & Nordström P, et al.2014 & & 108 & 45,141 & 458 & 765,915 \\
\hline 28 & Abner EL, et al. 2014 & & 8 & 158 & 31 & 452 \\
\hline 29 & Rasmusson DX, et al. 1995 & $A D$ & 20 & 1 & 48 & 33 \\
\hline 30 & Nemetz PN, et al. 1999 & & 31 & 1252 & 957 & 2783 \\
\hline 31 & Barnes DE, et al. 2014 & & 12 & 1217 & 1098 & 186,437 \\
\hline 32 & Spangenberg S, et al. 2009 & Parkinson & 87 & 73,232 & 8769 & $2,799,434$ \\
\hline 33 & Lee PC, et al. 2012 & & 42 & 50 & 315 & 704 \\
\hline 34 & Taylor KM, et al. 2015 & & 69 & 24 & 310 & 206 \\
\hline 35 & Gardner RC, et al. 2015 & & 891 & 51,502 & 1247 & 112,159 \\
\hline 36 & Kalkonde YV, 2012 & FTD (TDP-43) & 8 & 17 & 55 & 474 \\
\hline 5 & Wang HK, et al. 2015 & & 363 & 24,222 & 413 & 122,512 \\
\hline 37 & Chen H, et al. 2007 & ALS (TDP-43) & 24 & 42 & 85 & 213 \\
\hline
\end{tabular}




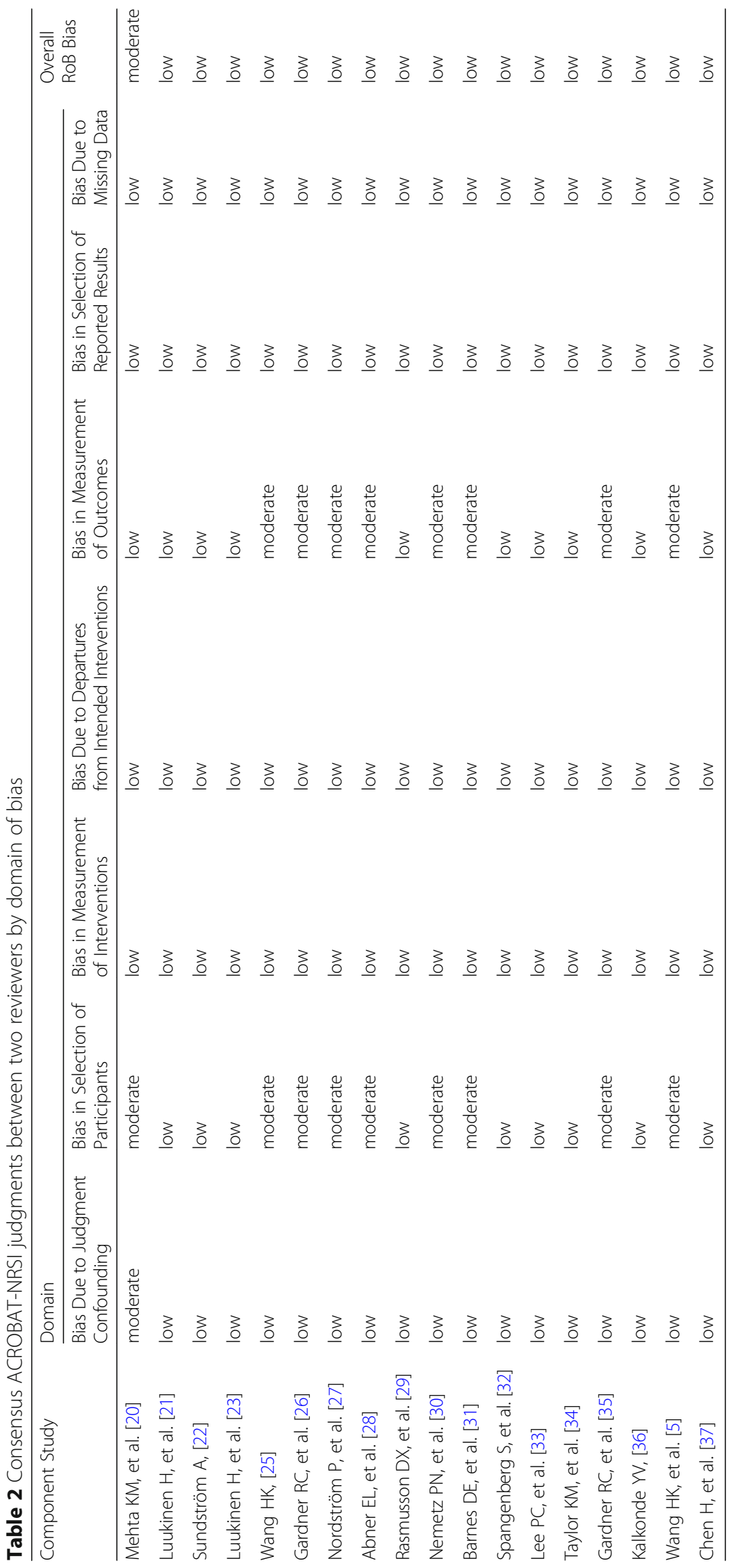




\begin{tabular}{|c|c|c|c|c|c|c|c|c|c|c|}
\hline Study or Subgroup & \multicolumn{2}{|c|}{ With TBI } & \multicolumn{2}{|c|}{ Without TBI } & Weight & $\begin{array}{l}\text { Odds Ratio } \\
\text { M-H, Random. } 95 \% \mathrm{Cl}\end{array}$ & \multicolumn{3}{|c|}{$\begin{array}{c}\text { Odds Ratio } \\
\text { M-H. Random, } 95 \% \mathrm{Cl}\end{array}$} & \\
\hline Abner EL, et al. 2014 & 8 & 166 & 31 & 483 & $87 \%$ & & & & & \\
\hline Gardner RC, et al. 2014 & 4361 & 51799 & 6610 & 115501 & $32.2 \%$ & $1.51[1.46,1.58]$ & & & & \\
\hline Nordström P, et al.2014 & 108 & 45249 & 458 & 766373 & $27.3 \%$ & $4.00[3.24,4.94]$ & & & - & \\
\hline Wang HK, 2012 & 1196 & 44925 & 3499 & 224685 & $31.8 \%$ & $1.73[1.62,1.85]$ & & & - & \\
\hline Total $(95 \% \mathrm{Cl})$ & & 142139 & & 1107042 & $100.0 \%$ & $1.93[1.47,2.55]$ & & & $>$ & \\
\hline Total events & 5673 & & 10598 & & & & & & & \\
\hline $\begin{array}{l}\text { Heterogeneity: } \mathrm{Tau}^{2}=0.0 \\
\text { Test for overall effect: } Z=\end{array}$ & $\begin{array}{l}\mathrm{Chi}^{2}=8 \\
4.70(\mathrm{P}<\end{array}$ & $\begin{array}{l}9.83, \mathrm{df}= \\
0.00001)\end{array}$ & $=3(P<0$. & $.00001) ; 1^{2}=$ & $=97 \%$ & & 0.01 & $\begin{array}{c}0.1 \\
\text { Favours control }\end{array}$ & $\begin{array}{l}10 \\
1\end{array}$ & 100 \\
\hline
\end{tabular}

Fig. 1 Individual and pooled odds ratios for dementia

radiological, and genetic characteristics, are characterized by TDP-43 aggregation [17]. Therefore, we defined ALS and FTD as TDP-43-associated diseases. Two authors (H.K. Wang or Y.C. Tai) examined the titles and abstracts of the studies found in the systematic literature search. The entire articles of potentially eligible studies were assessed to determine if the studies met the criteria. The study selection process was performed in accordance with the Preferred Reporting Items for Systematic Reviews and Meta-Analyses (PRISMA) guidelines and documented with a PRISMA flow diagram.

\section{Data analysis}

The effects of TBI on the neurodegeneration outcomes were assessed with a random effects model because the designs and patient populations of the observational studies were expected to be heterogeneous. The Odds Ratio (OR) and 95\% confidence intervals (CIs) were calculated. Statistical heterogeneity was examined with chi-square and I-squared $\left(\mathrm{I}^{2}\right)$ tests of heterogeneity. The data were analyzed with Review Manager (RevMan) Version 5.3 (Copenhagen: The Nordic Cochrane Centre, The Cochrane Collaboration, 2014).

\section{Results}

\section{The systematic search}

Using the search terms, our literature and reference list searches yielded 1317 references. After examination of the abstracts and, when indicated, the full texts of the articles, 68 studies were considered potentially relevant [18-37] . Finally, 18 studies met our inclusion criteria and were included in the meta-analysis. The characteristics of the included trials are listed in Table 1. Methodologic qualities of are shown in Table 2.

\section{The subgroup meta-analyses}

There was an association between TBI and subsequent dementia (pooled OR $=1.93,95 \% \mathrm{CI}=1.47-2.55$ ) (Fig. 1). However, this association does not concur with the apolipoprotein $\mathrm{E}$ (APOE) genotype (pooled $\mathrm{OR}=1.82$, 95\% $\mathrm{CI}=0.74-4.46)$ (Fig. 2). The studies associated with $\mathrm{AD}$ yielded a pooled OR of $1.03(95 \% \mathrm{CI}=0.06-16.33)$ with heterogeneity ( $\left.\mathrm{I}^{2}=98 \%, P<0.001\right)$ (Fig. 3 ). The analysis of the risk of TBI that was associated with PD yielded a pooled OR of $1.19(95 \% \mathrm{CI}=0.50-2.84)$ with heterogeneity $\left(\mathrm{I}^{2}=98 \%, \mathrm{P}<0.001\right)$ (Fig. 4). The analysis of the risk associated with TDP-43 and FTD yielded a pooled OR of $2.97(95 \% \mathrm{CI}=1.35-6.53)$ and $4.44(95 \% \mathrm{CI}=3.86-5.10)$ (Figs. 5 and 6).

\section{Discussion}

Concerns about the relationship between TBI and neurodegeneration have long existed. Our principal finding was that TBI is a potential risk factor for subsequent dementia (1.93, 95\% CI =1.47-2.55), TDP-43 (2.97, 95\% $\mathrm{CI}=1.35-6.53)$ and FTD (4.44, 95\% CI =3.86-5.10). However, when we analyzed the associations of the

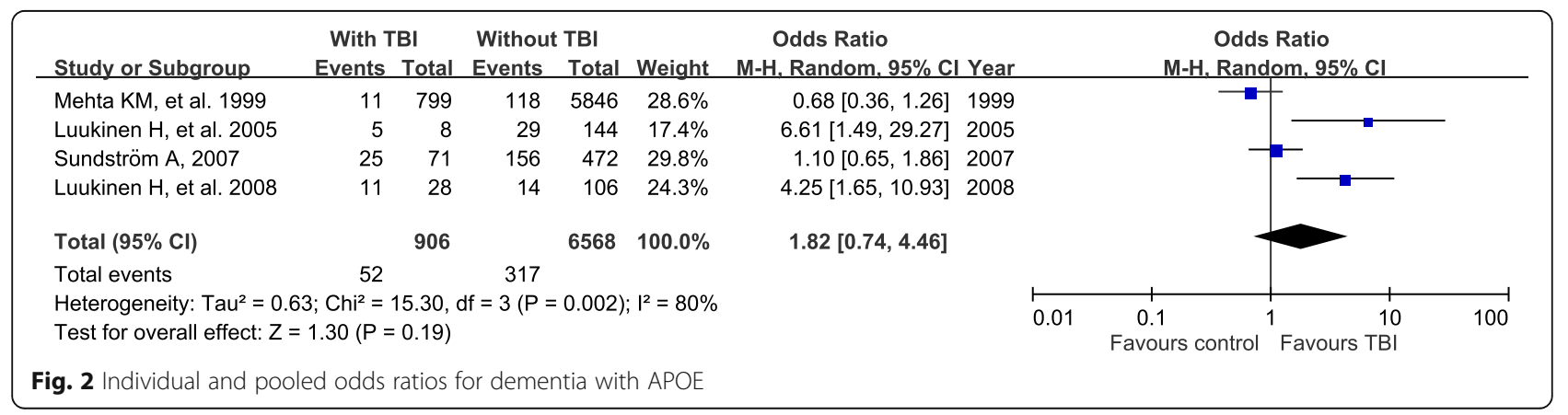




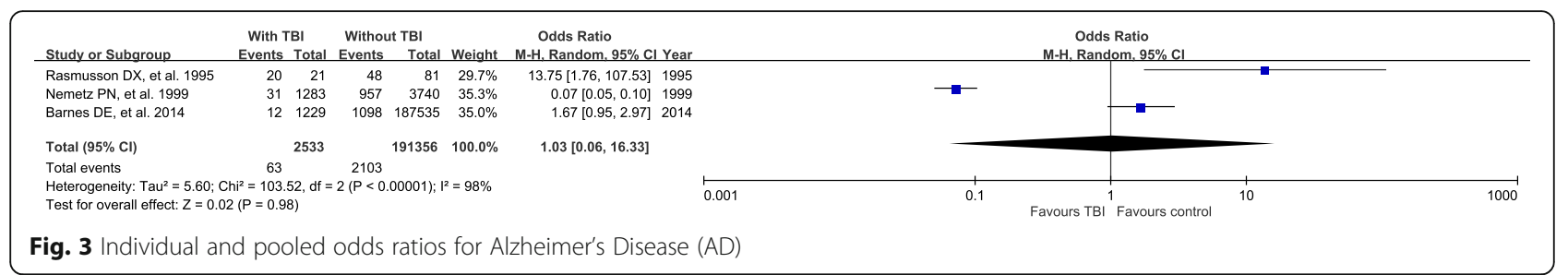

incidences of $\mathrm{AD}, \mathrm{PD}$, or dementia with APOE genotype, we found that TBI was not a risk.

A common factor between TBI and different neurodegenerative disorders is the abnormal aggregation, accumulation, and/or disposition of proteins in the brain. Patients with TBI have beta-amyloid deposition in their brains, and the pattern of deposition is similar to that observed in patients with AD. Amyloid precursor protein, $\beta$-Amyloid precursor protein-cleaving enzyme-1, and presenilin-1, which is a $\gamma$-secretase complex protein, serve as sources of amyloid- $\beta$ peptide deposition after TBI [5, 29-31].

TBI may also exacerbate nigrostriatal dopaminergic degeneration by modulating PD-associated genes. These results suggest that $\alpha$-synuclein is a pathological link between the chronic effects of TBI and PD symptoms [32-34].

Another mechanism that might link TBI to neurodegeneration is the accumulation of TDP-43 in patients with FTD and ALS [5, 24, 37]. Patients with chronic traumatic encephalopathy (CTE) exhibit widespread TDP-43 proteinopathy in multiple areas of the brain [38]. Some patients also had TDP-43 protein in their spinal cords, and these patients developed a progressive motor neuron disease several years before their deaths [38, 39]. These findings suggest that TDP-43-associated neurodegeneration and head trauma are connected.

The mechanisms underlying the association of TBI and the incidence of neurodegeneration are exceedingly complex. In fact, in TBI, multiple pathologies occur simultaneously. However, systematic analyses of multiple pathologies in individual cases in a large TBI and control population have not been conducted [913, 39]. Therefore, a significant association of $\mathrm{AD}$,
PD, and APOE-associated dementia was not observed, and no evidence that head trauma was a risk factor for patients with these disorders was found.

Another noteworthy finding of our study was that $\mathrm{AD}$ is not the most common form of neurodegeneration. Several studies have reported that TBI does not affect the development of AD. Whether a single occurrence of moderate-to-severe TBI triggers the development of neurodegeneration remains somewhat controversial [9-13]. In addition, brain injury has been shown to lead to the development of non-AD dementias. However, accurate clinical diagnostic criteria for neurodegeneration that results from TBI do not exist. Therefore, the true risk of neurodegeneration following TBI is hard to define.

Examinations of patients with CTE may help resolve this problem. The symptoms of CTE, which include behavioral disturbances, cognitive dysfunction, and/or motor-related symptoms, generally begin 8-10 years after repetitive mild TBIs are experienced [40-42]. However, the clinical diagnostic criteria for traumatic encephalopathy syndrome have only recently been reported. CTE can be seen after a single moderate or severe TBI while traumatic encephalopathy syndrome exhibits progressive deterioration over time. Therefore, clinical judgment must be used to determine whether the amount of progression is greater than what is expected for the age and comorbidities of the patient [39-42]. Multiple neurodegeneration processes have been used to describe the behavioral disturbances and cognitive dysfunction in patients following TBI owing to the lack of suitable diagnoses. This diagnosis can now be used to define those symptoms.

A major strength of this meta-analysis was the inclusion of a variety of different neurodegenerative outcomes

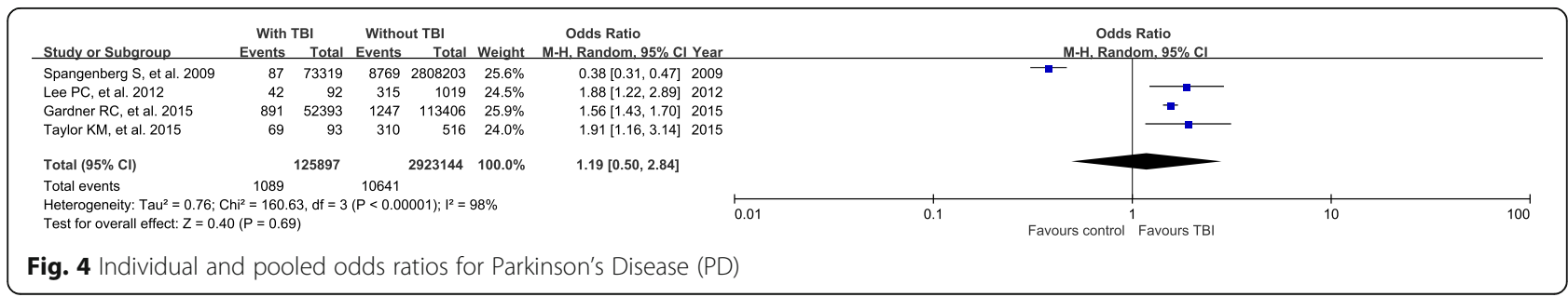




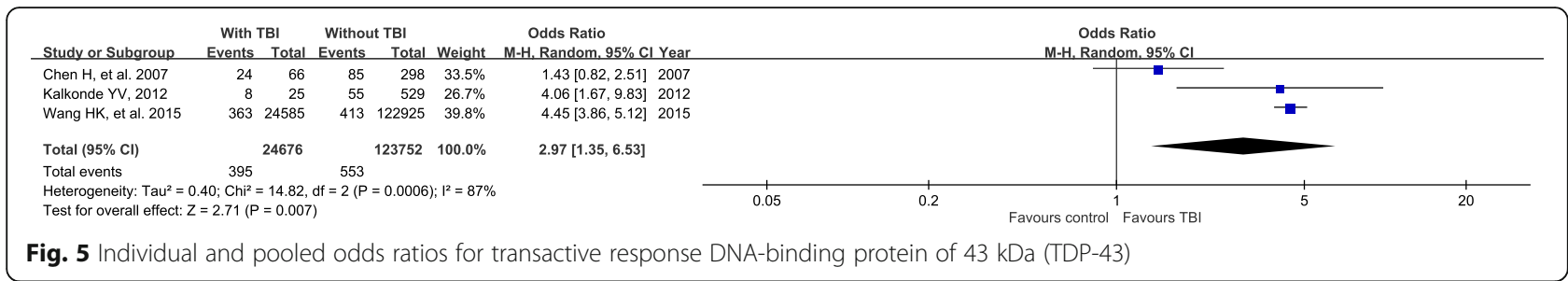

rather than a single diagnosis. The literature search was comprehensive because it focused on diagnoses rather than self-reported symptoms, which resulted in a rigorous examination of the topic.

However, several limitations of this meta-analysis warrant consideration. First, the initial severities of the TBIs varied within and across studies. Since our meta-analyses examined only published data, some important parameters, such as sex, alcohol consumption, and comorbidities were missing. Therefore, we were not able to control for these potential confounding factors. Patients with severe TBI had loss of high cortical function and presented in a vegetative state. In our studies, we included only patients who sought treatment for TBI and neurodegeneration disease, but not important parameters indicating clinical severity and imaging information on TBI. Therefore, it is hard to understand the relationship between the severity of TBI and neurodegeneration disease.

Second, we were not able to examine the effects of the locations of the TBIs in this analysis. Some investigators have proposed that temporal and frontal lobe lesions are more likely to be associated with an increased risk of later dementia compared with lesions in other brain regions [5]. In addition, preinjury intelligence and education level are also associated with TBI and dementia. However, the effects of these factors in this study were difficult to determine.

Another limitation was that none of the studies included in this review provided information on genetics [8]. The estimated effect of the apolipoprotein $\mathrm{E}$ (APOE) gene 4 on functional outcome might be greatly confounded by such factors, which could thus influence the validity of any meta-analysis that uses unadjusted results. Therefore, future studies on the relationship between $A P O E 4$ expression and the functional outcome of TBI should consider these important confounding factors. The age may also have an effect on the patients with neurodegeneration diseases. The risk between early-onset and late-onset neurodegeneration diseases maybe different. The patient with young onset neurodegeneration diseases more likely has a genetic or metabolic disease. However, neurodegeneration diseases are far more common in geriatric population, and researches in neurodegeneration disease are focused mainly on old persons. Therefore, it is hard to understand the association between age and neurodegeneration diseases in our study.

\section{Conclusion}

Patients with TBI frequently exhibit neurodegeneration. The symptoms of these neurodegenerative processes include behavioral disturbances, cognitive dysfunction, and/or motor-related symptoms. TBI is a potential risk factor only for subsequent dementia, TDP-43, and FTD, but not for AD, PD, or APOE-associated neurodegeneration. The epidemiology and pathology of this association have been difficult to establish. No suitable criteria define these neurodegenerative processes. However, the diagnosis of CTE may help to resolve this problem. Although the evidence suggested that TBI was a risk factor for neurodegeneration, there is limited information on the type, frequency, or amount of trauma that was necessary to induce the neurodegenerative processes. Therefore, further studies in this area are necessary to answer these questions and determine whether the proper management of TBI is effective in reducing the incidence of neurodegeneration.

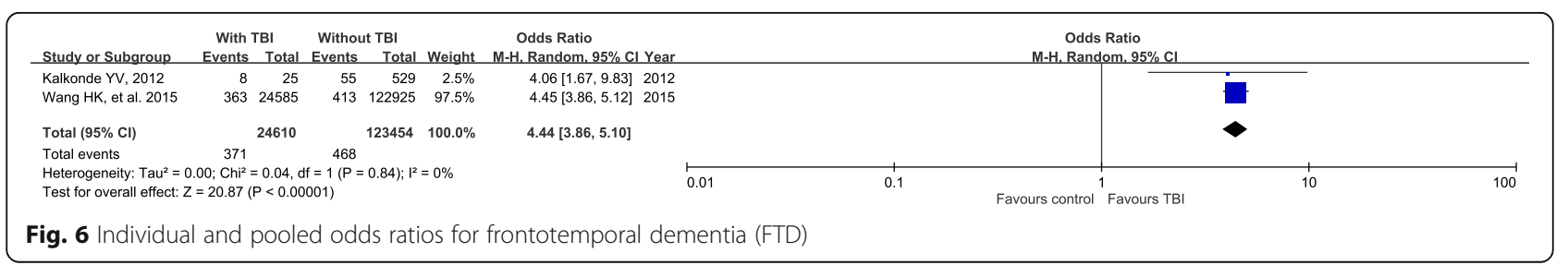




\section{Abbreviations}

AD: Alzheimer disease; ALS: amyotrophic lateral sclerosis;

APOE: apolipoprotein E; FTD: frontotemporal dementia (FTD); PD: Parkinson's disease; TBI: traumatic brain injury; TDP-43: transactive response DNA-binding protein of $43 \mathrm{kDa}$

\section{Acknowledgements}

This study was supported by Center for Database Research, E-DA HEALTHCARE GROUP.

\section{Funding}

No funding was received.

\section{Availability of data and materials}

The datasets analyzed during the current study are listed in Table 1.

\section{Authors' contributions}

$\mathrm{CHH}$ analyzed the data; CWL analyzed the data; YCL analyzed the data; $\mathrm{CYH}$ searched the papers; RYH analyzed the data; YCT examined the titles and abstracts of the studies found in the systematic literature search; KWW searched the papers and analyzed the data; SNY analyzed the data; YTS searched the papers; HKW examined the titles and abstracts of the studies found in the systematic literature search and was a major contributor in writing the manuscript. All authors read and approved the final manuscript.

\section{Ethics approval and consent to participate}

This study was based in part on data from the Medical Literature Analysis and Retrieval System Online (MEDLINE ${ }^{\circledR}$ )/PubMed (US National Library of Medicine, National Institutes of Health, Bethesda, MD; http://www.ncbi.nlm.nih.gov/ pubmed) database and Excerpta Medica Database (EMBASE ${ }^{\oplus}$, Elsevier, Amsterdam, Netherlands; http://www.elsevier.com/solutions/embasebiomedical-research).

\section{Consent for publication}

Not applicable.

\section{Competing interests}

The authors report no conflict of interest concerning the materials or methods used in this study or the findings specified in this paper.

\section{Publisher's Note}

Springer Nature remains neutral with regard to jurisdictional claims in published maps and institutional affiliations.

\section{Author details}

'Department of Family Medicine, E-Da Hospital, I-Shou University, Kaohsiung, Taiwan. ${ }^{2}$ School of Medicine for International Students, I-Shou University, Kaohsiung, Taiwan. ${ }^{3}$ Department of Nephrology, E-Da Hospital, I-Shou University, Kaohsiung, Taiwan. ${ }^{4}$ Neurosurgical Service, Department of Surgery, National Cheng Kung University Hospital, Tainan, Taiwan. ${ }^{5}$ Department of Neurology, E-Da Hospital, I-Shou University, Kaohsiung, Taiwan. ${ }^{6}$ Department of Neurosurgery, E-Da Hospital, I-Shou University, No.1, Yida Road, Jiaosu Village, Yanchao District, Kaohsiung City 82445, Taiwan. ${ }^{7}$ Department of Neurology, National Cheng Kung University Hospital, College of Medicine, National Cheng Kung University, Tainan, Taiwan.

\section{Received: 13 September 2017 Accepted: 21 October 2018}

Published online: 05 November 2018

\section{References}

1. Ghajar J. Traumatic brain injury. Lancet. 2000;356(9233):923-9.

2. Risdall JE, Menon DK. Traumatic brain injury. Philos Trans R Soc Lond Ser B Biol Sci. 2011 Jan 27;366(1562):241-50.

3. Ramlackhansingh AF, Brooks DJ, Greenwood RJ, Bose SK, Turkheimer FE, Kinnunen KM, Gentleman S, Heckemann RA, Gunanayagam K, Gelosa G, Sharp DJ. Inflammation after trauma: microglial activation and traumatic brain injury. Ann Neurol. 2011 Sep;70(3):374-83.

4. Masel BE, DeWitt DS. Traumatic brain injury: a disease process, not an event Neurotrauma. 2010 Aug;27(8):1529-40. https://doi.org/10.1089/neu.2010.1358.
5. Wang HK, Lee YC, Huang CY, Liliang PC, Lu K, Chen HJ, Li YC, Tsai KJ. Traumatic brain injury causes frontotemporal dementia and TDP-43 proteolysis. Neuroscience. 2015 Aug 6;300:94-103.

6. Fleminger S, Oliver DL, Lovestone S, Rabe-Hesketh S, Giora A. Head injury as a risk factor for Alzheimer's disease: the evidence 10 years on; a partial replication. J Neurol Neurosurg Psychiatry. 2003;74(7):857-62.

7. Rugbjerg K, Ritz B, Korbo L, Martinussen N, Olsen JH. Risk of Parkinson's disease after hospital contact for head injury: population based case-control study. BMJ. 2008;337:a2494.

8. Schmidt S, Kwee LC, Allen KD, Oddone EZ. Association of ALS with head injury, cigarette smoking and APOE genotypes. J Neurol Sci. 2010;291:22e9.

9. Launer LJ, Andersen K, Dewey ME, et al. Rates and risk factors for dementia and Alzheimer's disease: results from EURODEM pooled analyses. EURODEM Incidence Research Group and Work Groups European Studies of Dementia Neurology. 1999:52:78e84.

10. Fratiglioni L, Ahlbom A, Viitanen M, et al. Risk factors for late-onset Alzheimer's disease: a population-based, case-control study. Ann Neurol. 1993;33:258e66

11. Williams DB, Annegers JF, Kokmen E, et al. Brain injury and neurologic sequelae: a cohort study of dementia, parkinsonism, and amyotrophic lateral sclerosis. Neurology. 1991;41:1554e7.

12. Levy G, Tang MX, Cote $L$, et al. Do risk factors for Alzheimer's disease predict dementia in Parkinson's disease? An exploratory study. Mov Disord. 2002:17:250e7

13. Turner MR, Abisgold J, Yeates DG, et al. Head and other physical trauma requiring hospitalisation is not a significant risk factor in the development of ALS. J Neurol Sci. 2010;288:45e8.

14. Barthélemy EJ, Melis M, Gordon E, Ullman JS, Germano IM. Decompressive Craniectomy for severe traumatic brain injury: a systematic review. World Neurosurg. 2016 Apr;88:411-20.

15. Perry DC, Sturm VE, Peterson MJ, Pieper CF, Bullock T, Boeve BF, Miller BL, Guskiewicz KM, Berger MS, Kramer JH, Welsh-Bohmer KA. Association of traumatic brain injury with subsequent neurological and psychiatric disease: a meta-analysis. J Neurosurg. 2015;28:1-16.

16. Zhang BF, Wang J, Liu ZW, Zhao YL, Li DD, Huang TQ, Gu H, Song JN. Metaanalysis of the efficacy and safety of therapeutic hypothermia in children with acute traumatic brain injury. World Neurosurg. 2015;83(4):567-73.

17. Ferrari R, Kapogiannis D, Huey ED, Momeni P. FTD and ALS: a tale of two diseases. Curr Alzheimer Res. 2011;8(3):273-94.

18. Rapoport M, Wolf U, Herrmann N, Kiss A, Shammi P, Reis M, Phillips A, Feinstein A. Traumatic brain injury, apolipoprotein E-epsilon4, and cognition in older adults: a two-year longitudinal study. J Neuropsychiatry Clin Neurosci. 2008 Winter;20(1):68-73.

19. Tanner CM, Goldman SM, Ross GW, Grate SJ. The disease intersection of susceptibility and exposure: chemical exposures and neurodegenerative disease risk. Alzheimers Dement. 2014;10(3 Suppl):S213-25.

20. Mehta KM, Ott A, Kalmijn S, Slooter AJ, van Duijn CM, Hofman A, Breteler MM. Head trauma and risk of dementia and Alzheimer's disease: the Rotterdam study. Neurology. 1999:53(9):1959-62.

21. Luukinen $H$, Viramo $P$, Herala M, Kervinen K, Kesäniemi YA, Savola O, Winqvist S, Jokelainen J, Hillbom M. Fall-related brain injuries and the risk of dementia in elderly people: a population-based study. Eur J Neurol. 2005; 12(2):86-92.

22. Sundström A, Nilsson LG, Cruts M, Adolfsson R, Van Broeckhoven C, Nyberg L. Increased risk of dementia following mild head injury for carriers but not for non-carriers of the APOE epsilon4 allele. Int Psychogeriatr. 2007;19(1):159-65.

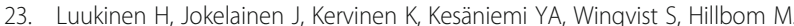
Risk of dementia associated with the ApoE epsilon4 allele and falls causing head injury without explicit traumatic brain injury. Acta Neurol Scand. 2008; 118(3):153-8.

24. Savica R, Parisi JE, Wold LE, Josephs KA, Ahlskog JE. High school football and risk of neurodegeneration: a community-based study. Mayo Clin Proc. 2012;87(4):335-40.

25. Wang HK, Lin SH, Sung PS, Wu MH, Hung KW, Wang LC, Huang CY, Lu K, Chen HJ, Tsai KJ. Population based study on patients with traumatic brain injury suggests increased risk of dementia. J Neurol Neurosurg Psychiatry. 2012;83(11):1080-5.

26. Gardner RC, Burke JF, Nettiksimmons J, Kaup A, Barnes DE, Yaffe K Dementia risk after traumatic brain injury vs nonbrain trauma: the role of age and severity. JAMA Neurol. 2014;71(12):1490-7. https://doi.org/10.1001/ jamaneurol.2014.2668 
27. Nordström P, Michaëlsson K, Gustafson Y, Nordström A. Traumatic brain injury and young onset dementia: a nationwide cohort study. Ann Neurol. 2014;75(3):374-81.

28. Abner EL, Nelson PT, Schmitt FA, Browning SR, Fardo DW, Wan L, Jicha GA, Cooper GE, Smith CD, Caban-Holt AM, Van Eldik LJ, Kryscio RJ. Self-reported head injury and risk of late-life impairment and $A D$ pathology in an $A D$ center cohort. Dement Geriatr Cogn Disord. 2014;37(5-6):294-306.

29. Rasmusson DX, Brandt J, Martin DB, Folstein MF. Head injury as a risk factor in Alzheimer's disease. Brain Inj. 1995;9(3):213-9.

30. Nemetz PN, Leibson C, Naessens JM, Beard M, Kokmen E, Annegers JF, Kurland LT. Traumatic brain injury and time to onset of Alzheimer's disease: a population-based study. Am J Epidemiol. 1999;149(1):32-40.

31. Barnes DE, Kaup A, Kirby KA, Byers AL, Diaz-Arrastia R, Yaffe K. Traumatic brain injury and risk of dementia in older veterans. Neurology. 2014;83(4): 312-9.

32. Spangenberg S, Hannerz H, Tüchsen F, Mikkelsen KL. A nationwide population study of severe head injury and Parkinson's disease. Parkinsonism Relat Disord. 2009;15(1):12-4.

33. Lee PC, Bordelon Y, Bronstein J, Ritz B. Traumatic brain injury, paraquat exposure, and their relationship to Parkinson disease. Neurology. 2012; 79(20):2061-6.

34. Taylor KM, Saint-Hilaire MH, Sudarsky L, Simon DK, Hersh B, Sparrow D, Hu $H$, Weisskopf MG. Head injury at early ages is associated with risk of Parkinson's disease. Parkinsonism Relat Disord. 2015.

35. Gardner RC, Burke JF, Nettiksimmons J, Goldman S, Tanner CM, Yaffe K. Traumatic brain injury in later life increases risk for Parkinson disease. Ann Neurol. 2015;77(6):987-95.

36. Kalkonde W, Jawaid A, Qureshi SU, Shirani P, Wheaton M, Pinto-Patarroyo GP, Schulz PE. Medical and environmental risk factors associated with frontotemporal dementia: a case-control study in a veteran population. Alzheimers Dement. 2012;8(3):204-10.

37. Chen H, Richard M, Sandler DP, Umbach DM, Kamel F. Head injury and amyotrophic lateral sclerosis. Am J Epidemiol. 2007;166(7):810-6.

38. Mckee AC, Gavett BE, Stern RA, Nowinski CJ, Cantu RC, Kowall NW, Perl DP, Hedley-Whyte ET, Price B, Sullivan C, Morin P, Lee HS, Kubilus CA, Daneshvar DH, Wulff M, Budson AE. TDP-43 proteinopathy and motor neuron disease in chronic traumatic encephalopathy. J Neuropathol Exp Neurol. 2010;69(9): 918-29

39. Daneshvar DH, Goldstein LE, Kiernan PT, Stein TD, McKee AC. Post-traumatic neurodegeneration and chronic traumatic encephalopathy. Mol Cell Neurosci. 2015;66(Pt B):81-90,

40. Washington PM, Villapol S, Burns MP. Polypathology and dementia after brain trauma: does brain injury trigger distinct neurodegenerative diseases, or should they be classified together as traumatic encephalopathy? Exp Neurol. 2016;275(Pt 3):381-8.

41. Perrine K, Helcer J, Tsiouris AJ, Pisapia DJ, Stieg P. The Current Status of Research on Chronic Traumatic Encephalopathy. World Neurosurg. 2017.

42. Ojo JO, Mouzon BC, Crawford F. Repetitive head trauma, chronic traumatic encephalopathy and tau: challenges in translating from mice to men. Exp Neurol. 2016 Jan;275(Pt 3):389-404.

Ready to submit your research? Choose BMC and benefit from:

- fast, convenient online submission

- thorough peer review by experienced researchers in your field

- rapid publication on acceptance

- support for research data, including large and complex data types

- gold Open Access which fosters wider collaboration and increased citations

- maximum visibility for your research: over $100 \mathrm{M}$ website views per year

At $\mathrm{BMC}$, research is always in progress.

Learn more biomedcentral.com/submissions 